\title{
PRESENT AND FUTURE FUNCTIONS OF CANADA'S FORESTS
}

\author{
BY LOREN L. BROWN \\ Timber Controller for Canada
}

$T$

HE IMPORTANCE of the forests in the economic life of Canada has been illustrated in many ways, but none can be more striking than the part they are now playing in the war effort of this country and the Empire. Record-breaking exports of lumber to the United Kingdom, the vast quantities of wood supplied for defence construction in Canada, and the large volumes of foreign exchange obtained through the exports of forest products to non-Empire countries, speak for themselves.

Successful prosecution of the war overshadows all other considerations whatsoever, and all the wood needed for that purpose must be taken from the forests. With this general principle no one can quarrel. But the present emergency does not justify unnecessary devastation of the forest estate by the adoption of improper logging methods, and the very urgency of the situation makes imperative the best possible protection of the forests against wastage by fire and other enemies.

Wood is one of our chief raw materials and on forest products no expenditure of foreign exchange is necessary. Therefore, if we are to put forth our maximum war effort, we must use wood for all the many purposes for which it is suitable, and reduce consumption of imported or more expensive substitutes. Canadian architects and engineers must be brought to appreciate the merits of wood as a building material, if only to promote the conservation of foreign exchange. Through use of the modern ring. connectors it was possible to frame hundreds of large structures in timber last year, thus avoiding substantial increases in our already large imports of foreign steel. This process should be carried further, restoring wood to its proper place in the Canadian building industry.

Certain Canadian species are playing especially significant parts in the war. Sitka spruce is without an equal for structural components of wooden aircraft, and yellow birch yields the finest veneers for making plywood wing and fuselage coverings. These two species are now being used together, in the form of so-called "densewood," for the manufacture of aircraft propellers.

Supplying the forest products needed to meet the present crisis is the paramount consideration now, but eventually the war will come to an end. Then intricate questions respecting the supply of raw materials for our widespread forest industries will have to be solved. The chief function of the forests after the war will be what it has always been, namely, the maintenance of industries which can provide employment and help to maintain our people. I believe it is the function of the Canadian Society of Forest Engineers to lay plans now that will provide for the perpetuation of our forests in future. It is gratifying to know that the Sections of the Society have been expending great efforts in the formulation of a Forest Policy, and that preparation of a statement of policy for the Society as a whole is in progress. 
Foresters in Canada have three main tasks to perform: first, the protection of the forests we now have; second, the development of Canadian silviculture and management on a practical basis so that raw materials can be provided for industry in perpetuity at reasonable cost; and third, the education of the public respecting the importance of forests to the welfare of this country and the necessity for their better care.

The problems facing the profession are extremely diffcult and are a worthy challenge to every member of the Society. The degree to which they can successfully be answered will be the measure of the service that the profession has been able to give to our country. 